Editorial

\title{
Circadian rumination: nutritional insights
}

\begin{abstract}
This editorial addresses some important circadian patterns of rumination in ruminants of food-producing nature. Rumination is a crucial bioprocess during which the rumen environment maintains its buffering capacity towards functioning and optimal health. As a result, the health of the host ruminant and optimal production of microbial mass depend largely on successful and durable rumination. Research is required to discover circadian patterns of rumination in high-producing dairy and beef cattle under varying managemental conditions.
\end{abstract}

Keywords: rumination, circadian pattern, nutrition, health
Special Issue - 2015

\author{
Akbar Nikkhah \\ Department of Animal Sciences, University of Zanjan, Iran
}

Correspondence: Akbar Nikkhah, Chief Highly Distinguished Professor, Department of Animal Sciences, Faculty of Agricultural Sciences, University of Zanjan, Foremost Principal Highly Distinguished Elite-Generating Scientist, National Elite Foundation, Iran, Email anikkha@yahoo.com

Received: November 10, 2015 | Published: November 13, 2015

\section{Introduction}

Rumination is regurgitating the food already ingested and rechewing for optimal rumen microbial adherence and fermentation under well-neutralized conditions. Rumination is greatly determining in successful ruminant production and is related to resting that occurs when the ruminant is relaxed and not environmentally disturbed. Cows usually ruminate between $6-8 \mathrm{~h}$ daily. Rumination takes place mostly overnight, between $2000 \mathrm{~h}$ and $0800 \mathrm{~h}$ when little eating and grazing occur. The most intensive rumination occurs between $2200 \mathrm{~h}$ and $0600 \mathrm{~h}$ in day-fed animals. Sheep fed twice daily at $12 \mathrm{~h}$ intervals, exposed to $12 \mathrm{~h}$ light and $12 \mathrm{~h}$ dark period, possess diurnal rhythmicity in rumination. Thus, light does not seem to be a major cue affecting diurnal variation in rumination. The key factors regulating the initiation and cessation of rumination under different production systems will yet to be fully described. Rumination in sheep possesses diurnal patterns without a clear dependence on timing of feeding. In sheep fed at 1200, 2000, 0000, and 0800h, the maximal rumination occurs in the early morning (0400-0800h) and the minimum during the afternoon. The sheep fed at $0400 \mathrm{~h}$ and $1600 \mathrm{~h}$ peaks in rumination between $0000 \mathrm{~h}$ to $0400 \mathrm{~h}$. When time of feeding coincides with the time of greatest ruminating activity $(0400-0800 \mathrm{~h})$, feeding inhibits the rumination. ${ }^{1-5}$

The rumen contents and rumination duration are positively correlated in dairy cows. The greater rumen contents or greater rumen fiber load may stimulate bolus formation required for rumination. This stimulatory impact would be more pronounced when the meal is more fibrous because it can increase the intake of physically effective fiber and stimulate chewing activity. Increasing the hay intake increases the rumination time in ruminants. However, the positive response in rumination time to the hay intake is linear in single meal-fed rams but curvelinear in sheep with continuous access to feed. Despite changing diurnal rumination patterns, shifting herbage allocation time from $0700 \mathrm{~h}$ to $1500 \mathrm{~h}$ does not affect total daily rumination time. .,2,6 $^{1,2}$ However, the rumination and idling (no eating or ruminating activity) occurs mostly in the morning and afternoon after shifting grazing time from morning to the evening. Feeding in morning vs. evening entirely changes diurnal rumination patterns without affecting total daily rumination time. Such information is lacking for many types of ruminants of especially dairy cows fed once or multiple times daily under intensive production systems, requiring future research. ${ }^{7,8}$

Research is also highly required on discovering circadian rumination patterns and duration under varying managemental scenarios in high-producing dairy and beef cattle. Such knowledge is of crucial significance towards optimal nutritional management of food-producing ruminants.

\section{Acknowledgments}

Thanks to the Ministry of Science Research and Technology, and National Elite Foundation for supporting the author's global initiatives and programs of optimizing science edification in the third millennium.

\section{Conflict of interest}

Author declares that there is no conflict of interest.

\section{References}

1. Nikkhah A. Time of feeding an evolutionary science. Germany: LAP LAMBERT Publishing, GmbH \& Co. KG; 2011.

2. Nikkhah A. New Theories of Ruminant Feed Intake Regulation (In Persian). Tehran \& Zanjan: Jahade-Daneshgahi Publishers; 2014.

3. Nikkhah A. Eating time: an evolutionary manager of postmodern rumen physiology and health: a review. Open Access Animal Physiology. 2011;3:13-19.

4. Nikkhah A. Chronophysiology of ruminant feeding behavior and metabolism: an evolutionary review. Biol Rhythm Res. 2013;44(2):197-218.

5. Nikkhah A. Animal Chronophysiological Management: An Emerging Bioscience. Open Access Animal Physiology. 2011;3:9-12.

6. Nikkhah A. On Rumen Microbial Evolution: Food Security Prospects. $J$ Food Nutri. 2015;2(2):011.

7. Nikkhah A. Timely Provision of Different Feeds in Dairy Enterprises: A Circadian Science. Adv Dairy Res. 2015;3:1.

8. Nikkhah A. Gut Adaptation to Healthy Starch Assimilation in Dairy Ruminants: A Lifetime Development. Adv Dairy Res. 2015;3:e117. 